\title{
Occupational cancer: interaction with life style factors
}

\author{
F.J.C. Roe \\ Independent Toxicologist and Experimental Pathologist, 19 Marryat Road, Wimbledon Common, \\ London $S W 195 B B, U K$.
}

\begin{abstract}
Summary: It is argued that as the major occupational cancer risks become matters of historical interest, research epidemiologists working in the field should broaden their approaches to encompass life style factors. In the investigation of possible low-cancer risks, it no longer makes any sense to confine their data-collecting activities solely to exposure to dusts and chemicals at work and to regard exposure to chemicals at home, in the garden or during leisure activities simply as possible confounding variables. Furthermore it is becoming more and more meaningless to undertake any epidemiological investigation aimed at detecting or defining a low level of cancer risk without taking into account what and how much, for example, people eat, drink and smoke. Possible exposure to chemicals at work is increasingly becoming a source for confounding variables in relation to life-style-associated cancer risks, as distinct from life-style being a source of confounding variables in epidemiological studies of occupation-associated cancer risks.
\end{abstract}

\section{Introduction}

During the last few decades spectacular advances in the science and practice of industrial hygiene have led to dramatically reducing risks of cancer from known potent carcinogens in the workplace.

This is true for exposure to asbestos, mineral oils, aromatic amines and various metal-containing fumes and dusts. More importantly, the philosophical approach has changed. Nowadays the chemical industry does not wait until a new hazard is suspected, instead, designs for new industrial plants are drawn up on the assumption that there may be dangers to workers from exposure to dusts and fumes and therefore such exposure is minimized or completely prevented by the total enclosure of chemical processes.

The nature of carcinogenesis is such that the effects of exposure to a genotoxic carcinogen tend to persist long after exposure has ceased. For this reason cancers are still being seen in middle-aged and elderly persons which relate to their exposure to chemicals and dusts at work many years previously. This is bound to go on happening until well into the next century. In the meantime, life is becoming more difficult for the young and ambitious epidemiologist struggling to make his name by identifying a new occupational cancer hazard or by quantifying an already recognized hazard in a way that is relevant to modern practices.

Correspondence: F.J.C. Roe., D.M.(Oxon), D.Sc. (Lond), F.R.C.Path.

Received: 20 November 1989
One way out of the dilemma is to try to organize studies in developing countries where occupational hygiene standards are in some cases still very low. Certainly there remains great scope for useful and important research in such countries, using local scientific talent boosted by Western equipment, methodology and science. But how should the occupational cancer researcher be thinking about his future role? In this article it is suggested that it is becoming increasingly difficult to distinguish between possible low cancer risks from known or unknown carcinogens at work and life-style factors. At present the latter tend to be regarded merely as confounding variables by occupational cancer epidemiologists whereas, since life-style factors are implicated in the causation of at least ten times as many cancers as work-associated chemicals, it surely should be the latter and not the former that are placed in the category of potentially confounding variables? $A$ fortiori, the need for this shift of emphasis amounts to no more than simple common sense insofar as many people are exposed to far more chemicals and dusts in their houses and gardens and during their leisure activities than they ever are at work. Also, what and how much people eat, drink and smoke simply cannot any longer be ignored in any meaningful survey of possible low level occupational health risk.

During recent years industry has been increasingly pressed not only to protect their workforce from exposure to toxic chemicals and measure what they are exposed to, but also to monitor the health of their workers for evidence of possible 
work-related toxic effects, including increased cancer risk. It is suggested that most of the data that are being collected in response to this pressure will be of little or no value unless data on life-style factors are also assiduously collected. The basis for these views is the subject of the present article.

\section{Definitions of occupation and cancer}

Let us first consider the terms 'occupation' and 'cancer'. Except for the idle and drop-outs, and for those unfortunates who are never healthy enough to undertake any work, everyone has an 'occupation' at least during part of their lives. Chauvinists may hold the view that the housework that housewives do is not real work, but that is not how the housewives themselves see it. Students certainly regard their studying as work. In most people's minds, cancer is a fatal or potentially fatal malignant neoplastic disease which, if not treated, progresses by local extension and/or metastatic growth. The diagnosis 'cancer' does not encompass benign neoplasms such as skin warts or benign non-invasive glandular adenomas, even though such lesions may sometimes cause death by haemorrhage or obstruction or may undergo progression from benign to malignant.

Given these rough definitions of occupation and cancer, and given that between one-in-three and one-in-four people develop one or other type of cancer during their life-time and between one-infour and one-in-five people die from cancer, it should surprise no-one that no occupational subgroup is devoid of all risk of developing cancer.

Despite the obvious common sense of this statement, it would be hard to find any occupational health institute that regarded itself as concerned with 'housework' or 'studying' as an 'occupation'. This is because it has become fixed in some people's minds first, that most cancers are caused by exposure to environmental chemicals; secondly, that the chemicals concerned are xenobiotic; and thirdly, that, for an occupation to be associated with an increased risk of cancer development, it must involve exposure to a carcinogenic chemical.

\section{The relationship between occupation and cancer risk}

If, for the sake of argument, we accept that all people have an occupation and that on average, irrespective of the nature of that occupation, they enjoy an average life-span of $70-75$ years and have a $20 \%$ chance of dying from one or other form of cancer, then in order to study the relationship between occupation and cancer risk we need to be able to compare data for definable sub-groups with the data for the whole population. This is done in the UK Registrar General's Occupational Mortality Decennial Supplement (1970-1972). ${ }^{1}$ When looking at occupational mortality data such as these, many people only look for evidence of increased cancer risk, whereas it is not at all unreasonable to suppose that some occupations are associated with decreased cancer risks. Ramazzini, the founder of occupational medicine, reported an increased incidence of breast cancer among nuns. Doubtless this was offset by a decreased incidence of cancer of the cervix uteri. Today we know that a successful pregnancy before the age of thirty protects against breast cancer ${ }^{2}$ while an indulgence in multiple sexual partners predisposes to cervical cancer. ${ }^{3}$ Thus one can argue the case either way. On the one hand one may conclude that occupation as a nun increases breast cancer risk and decreases risk of cervical cancer. On the other hand one may contend that the increased incidence of breast cancer and decreased risk of cervical cancer in nuns have nothing to do with occupation as a nun but is attributable to a confounding life-style variable, namely, the sexual habits (or rather the lack of them) of nuns.

If the reader thinks that too heavy weather has been made of this point, let him pause for a moment to reflect that according to the UK Registrar General's 1970-72 Occupational Decennial Supplement $^{1}$ significantly higher than average proportional mortality ratios for breast cancer are recorded for clerks, cashiers, typists, shorthand writers, secretaries, school teachers and social workers. Some, but certainly not all, of these occupations may be associated with late marriage or with first pregnancies delayed until after the age of thirty. On the other hand, all these occupations are relatively sedentary in nature compared with housework, shopping, and coping with young children. The question is which is more likely: is it that exposure to indoor air pollution in offices, to ozone from photocopiers, to solvents in inks or white-out fluids, or to blackboard chalk predisposes to breast cancer? Or is it that housework protects against breast cancer? Or are the data so unreliable that one could not substantiate any such hypothesis?

Achievements in the field of occupational cancer and the need for continuing vigilance

In the course of presenting the view that the philosophy underlying present-day approaches to occupational cancer risk needs to be reviewed, I should not like it to be thought that I am unaware of the achievements of past research in this field. Undoubtedly countless thousands of people have been, and are still being, protected from exposure to true carcinogens as a consequence of such 
research and of the introduction of regulations and occupational hygiene standards. Nor would I wish it to be thought that I am suggesting that continuing vigilance is not needed lest existing occupational cancer hazards have been overlooked or new ones are introduced. On the contrary I am pointing out that epidemiologists who fail to take fully into account life-style factors are most unlikely to pinpoint an occupation-related factor which only slightly increases the risk of any common type of cancer.

In 1981, Doll and Peto's ${ }^{4}$ best estimates of the relative contribution of occupational-related factors to cancer mortality in the United States was $4 \%$ (range $2-8 \%$ ) of all cancers. From the total they arbitrarily (but reluctantly) excluded skin and lip cancers in outdoor workers, alcohol-associated cancers in barmen, cancer of the cervix in prostitutes and breast cancer in nuns, because they considered that it is not conventional to regard such cancers as 'occupational' in nature. By comparison diet-related factors contribute $35 \%$, tobacco $30 \%$, reproductive and sexual behaviour $7 \%$ and alcohol $3 \%$. They supported these estimates with a careful and wide-ranging consideration of data of many different kinds apart from epidemiological data.

Table I illustrates Doll and Peto's conclusions with respect to the types of cancer which can undoubtedly arise from exposure to occupational hazards. Only in the case of deaths from cancer of the pleura and upper respiratory tract is the likely contribution of occupational factors as high as $25 \%$ and this only in males.

Table I Occupation-related cancer mortality as a $\%$ of mortality from all cancers of selected sites (from Doll \& Peto, $1981^{4}$ )

\begin{tabular}{|c|c|c|}
\hline Site of cancer & Males & Females \\
\hline Bone & 4 & 1 \\
\hline Larynx & 2 & 1 \\
\hline Leukaemia & 10 & 5 \\
\hline Liver & 4 & 1 \\
\hline Lung & 15 & 5 \\
\hline Mesentery \& peritoneum & 15 & 5 \\
\hline $\begin{array}{l}\text { Pleura, nasal sinuses \& } \\
\text { respiratory sites other } \\
\text { than larynx and lung }\end{array}$ & 25 & 5 \\
\hline Prostate & 1 & - \\
\hline Skin other than melanoma & 10 & 2 \\
\hline Urinary bladder & 10 & 5 \\
\hline Other & 6.8 & 1.2 \\
\hline $\begin{array}{l}\text { Estimated total } \\
\text { occupation-related cancer } \\
\text { deaths as a \% of all } \\
\text { cancer deaths }\end{array}$ & \multicolumn{2}{|c|}{4 (Range 2-8) } \\
\hline
\end{tabular}

\section{The need to update the present popular paradigm} relating to cancer aetiology

The fact that the spectra of the commonest types of fatal cancers in different countries vary widely and the fact that migrants from one culture to another (e.g. people migrating from Japan to the USA) tend to adopt the cancer spectrum of the country to which they move ${ }^{5}$ provided strong evidence in the early 1970s that environmental, as distinct from genetic, factors are mostly (e.g. 80-90\%) contributory to human cancer risk. Nor do any recent developments in the fields of epidemiology or cancer research suggest that this is not true. It is the next steps in the current paradigm that need to be seriously questioned. In so far as it has proved possible to produce cancers in laboratory animals by exposing them to mutagens, and in so far as many man-made chemicals that are in everyday use have mutagenic potential (i.e. are either directly mutagenic or can be converted to mutagens in the human body by metabolic activation), the idea has arisen that $80-90 \%$ of human cancers are due to exposure to environmental mutagens. Coupled with this idea has been the 'undisprovable' theory that there is no threshold dose below which a DNA-damaging chemical has no adverse effect on cancer risk, and also a strongly held belief that only man-made chemicals can be carcinogenic. These parts of the paradigm have led to the development of a contract research industry largely geared to the testing of xenobiotic chemicals for mutagenic activity and carcinogenic activity.

Nowadays every new chemical be it a drug, food additive, pesticide, cosmetic, domestic or industrial chemical, is submitted to one or more of a battery of tests for mutagenicity and carcinogenicity, and regulators busy themselves deciding whether or not to permit the use of the chemicals that have given positive results in one or more such tests. I do not suggest that all this laboratory and regulatory effort is a complete waste of resources, but I do suggest that it is most unlikely to lead to any significant reduction in the incidence of cancer or in the proportion of deaths that are due to cancer.

Specifically in relation to occupational cancer risk, if only $4 \%$, or even $8 \%$, of cancers are due to occupation, then no amount of testing of the chemicals used by industry and no system of statutory requirements to prevent the exposure of work people to genotoxic chemicals is going to have more than a small impact on the overall incidence of cancer.

As a first step, in updating the paradigm, one needs to consider carefully four very important facts. Firstly, there are now known to exist many substances which under certain circumstances can enhance cancer risk but which are neither genotoxic themselves nor metabolized to genotox- 
ins. An obvious example from the field of industrial toxicology is asbestos. In no ordinary sense is asbestos genotoxic. Almost certainly the cancers that arise in response to exposure to asbestos do so as a consequence of the chronic inflammatory and fibrotic changes which asbestos induces in the lungs. Of course there still exist those who mistakenly believe that genetic damage is an essential first step in the carcinogenic process. Guided by this false belief, some researchers continue to devise more and more ingenious ways of discovering the genetic damage which they are convinced that asbestos does. However, they would do better and waste less of their own time if they would just pause to read the growing literature on non-genotoxic mechanisms in carcinogenesis. ${ }^{6,7}$ How does it come about that ovariectomy followed by implantation of one of the ovaries into the spleen of the same animal gives rise to tumours of the pituitary and ovary? ${ }^{8,9}$ How is it that the natural hormone, $17 \beta$-oestradiol given to male hamsters gives rise to malignant tumours of the kidney? ${ }^{10}$ Why do rats develop benign and malignant adrenal medullary tumours simply as a consequence of being fed on a diet containing an unnaturally high concentration of lactose, the natural sugar of milk? ${ }^{11}$ None of these examples involve exposure to genotoxins or substances that are metabolizable to genotoxins. On the other hand all these examples involve major disturbances of physiological status.

Secondly, it should now be accepted that, under some circumstances at least, chronic inflammation does predispose to cancer. The possibility that this is so has long been entertained. However, the theory tended to be rejected with the discovery of chemicals which specifically cause cancer without necessarily giving rise to evidence of irritation. At this point 'irritation' was accredited with only a possible secondary role in carcinogenesis, i.e. as a co-carcinogen (something that enhances the effects of a carcinogen) or as a tumour-promoter (something which promotes the development of cancer after exposure to a mutation-causing genotoxic tumour initiator). In the absence of prior or concomitant exposure to a genotoxin, chronic irritation could play no role in carcinogenesis according to these theories.

I do not suggest that mutation is not, at some point, a required step in all carcinogenesis, even in carcinogenesis by natural hormones (such as $17 \beta$ oestradiol) or natural nutrients (such as lactose) or by fibrogenic irritants (such as asbestos). However, I do suggest that genotoxic damage is not the first step in these examples of carcinogenesis. Instead it is a late step and one that is made more likely to occur because of a prolonged disturbance of hormonal or physiological status or because of chronic irritation. I have recently reviewed these aspects of cancer theory elsewhere. ${ }^{12}$
Thirdly, even if the old paradigm was right and it were true that the first stage in the causation of all cancers results from exposure to an environmental mutagen, then there would still be absolutely no justification for assuming that the only important environmental mutagens are man-made xenobiotic chemicals. Bruce Ames eloquently shattered this myth in $1983 .{ }^{13}$ In this paper he listed numerous naturally-occurring mutagens and pointed out that such substances have persisted throughout the process of evolution because plants and animals have needed to produce toxins for the purpose of their own survival. In this context Ames invented the term 'Nature's pesticides'. In any event it is clear that some of the most potent genotoxins (such as aflatoxin) are not man-made chemicals but naturally- occurring ones. Also, it is clear that from the birth of time plants and animals, including man, have evolved in a 'sea of mutagens' (e.g. 3,4-benzopyrene and other carcinogenic polycyclic aromatic hydrocarbons formed during naturallyoccurring forest fires). For evolution to proceed as successfully as it has done, it was necessary for there to develop mechanisms for the repair of genotoxic damage in multicellular organisms. Consequently, it is not surprising, firstly that body cells have efficient mechanisms for repairing many kinds of DNA damage, and secondly that for DNA damage to lead to cancerous change it usually has to be extensive. Carcinogenesis by oncogenes or viruses involves replication of whole sequences of nucleic acids.

Fourthly, any theory of carcinogenesis based on the importance of exposure to electrophilic genotoxic chemicals cannot reasonably ignore the fact that elecrophiles are generated endogenously during the normal metabolism of natural foodstuffs. According to Ames ${ }^{13,14}$ and Totter ${ }^{15}$ naturallyoccurring endogenous metabolic processes lead to four different kinds of DNA damage: oxidation, methylation, deamination and depurination. Of these, oxidation is the most important. Evidence of oxidative DNA damage is provided by the presence of DNA breakdown products in urine. In comparisons of different species (mouse, rat and man) Ames ${ }^{14}$ found good correlations between longevity, metabolic rate and the rate of excretion of DNAbreakdown products in urine.

It has always been a puzzle that in humans who live on average to an age of $70+$ years, overall cancer incidence remains low until about age 50 and thereafter rises logarithmically with age. In rats the same pattern is seen but the time span is truncated to a longevity of about 36 months with spontaneous cancer incidence remaining low until about 24 months before rising in a logarithmic way. In humans aged $50+$ and in rats aged 24 months + , the logarithmically rising cancer risk is associated with logarithmically rising incidences of 
ageing-related non-neoplastic diseases. Ageing humans develop degenerative changes in their blood vessels (atheroma), hearts (coronary occlusion), muscles, joints and eye lenses etc. Ageing rats develop degenerative changes in their kidneys (progressive nephropathy), blood vessels (polyarteritis), spinal cord and cauda equina (radiculo neuropathy), and heart (chronic myocarditis) etc. Why does it take 50 years for the incidence of both ageing changes and cancer to start increasing ever more rapidly in humans but only 24 months for this to happen in rats? Ames ${ }^{14}$ suggests that the difference is explained by the difference in general metabolic rate between the two species.

Elsewhere $^{12}$ I have taken this theory a step further. It had always puzzled me that cancers caused by natural hormones (such as $17 \beta$-oestradiol) or nutrients (such as lactose) look exactly like other cancers. In other words there is no reason to think that the cells of which such cancers are composed are not clones of mutant cells. But why should mutations occur in response to non-mutagenic stimuli? I suggest the answer is that the administration of hormones leads to proliferation and increased metabolism in specific cells and that persistent cellular proliferation and high metabolic rate are associated with local increases in the generation of DNA-damaging electrophiles. In other words prolonged hormonal stimulation increases the risk of genetic damage by locally produced endogenous electrophiles.

\section{Life-style factors and ageing}

In humans the term 'life style' encompasses, inter alia, smoking, eating, alcohol consumption and sexual activities. The least effectively researched of these is eating. Smoking, alcohol and permissive sexual activities are not vices permitted in the case of laboratory rats. However, they are permitted to overeat, and, having little better to do, they freely indulge in gluttony.

My colleagues and $\mathrm{I}^{16}$ are presently engaged in harvesting the findings in a two and a half year study in which 12 groups each of 50 male and 50 female Wistar rats were fed on different diets and dietary regimes. The groups fed on low energy diets

Table II Effect of eating too much on survival, ageing-related degenerative disease, benign tumour incidence and premature death from cancer in unemployed Wistar rats: Preliminary data* (see Acknowledgements)

\begin{tabular}{|c|c|c|c|c|c|c|}
\hline & \multicolumn{3}{|c|}{ Males } & \multicolumn{3}{|c|}{ Females } \\
\hline & Ad lib & $\begin{array}{l}80 \% \text { of } \\
\text { ad lib }\end{array}$ & $\begin{array}{l}\text { Significance of } \\
\text { difference: }\end{array}$ & Ab lib & $\begin{array}{l}80 \% \text { of } \\
\text { ad lib }\end{array}$ & $\begin{array}{l}\text { Significance of } \\
\text { difference: }\end{array}$ \\
\hline Total no. of rats & 100 & 100 & & 100 & 100 & \\
\hline \multicolumn{7}{|l|}{$\%$ Survival from start of study** } \\
\hline Week 80 & 91 & 99 & & 94 & 96 & \\
\hline 105 & 66 & 87 & -- & 78 & 88 & -- \\
\hline 130 & 35 & 69 & & 41 & 76 & \\
\hline \multicolumn{7}{|l|}{$\begin{array}{l}\% \text { with ageing-associated degenerative } \\
\text { diseases }\end{array}$} \\
\hline Moderate or severe nephropathy & 70 & 3 & --- & 63 & 2 & -- \\
\hline Polyarteritis & 20 & 5 & --- & 19 & 0 & -- \\
\hline Moderate or severe myocarditis & 8 & 2 & NS & 5 & 0 & $(-)$ \\
\hline Acute prostatitis & 20 & 4 &.- & & & \\
\hline \multicolumn{7}{|l|}{ Non-fatal benign tumours } \\
\hline Total tumours & 114 & 79 & -- & 119 & 70 & -- \\
\hline \multicolumn{7}{|l|}{$\begin{array}{l}\% \text { with one or more malignant } \\
\text { tumour*** }\end{array}$} \\
\hline One or more & 39 & 13 & -- & 33 & 18 & --- \\
\hline More than one & 4 & 0 & - & 5 & 1 & NS \\
\hline Skin and adnexia & 9 & 3 & $(-)$ & 3 & 0 & NS \\
\hline Subcutaneous and connective tissue & 11 & 4 & - & 4 & 3 & NS \\
\hline Lymphoma & 6 & 0 & NS & 3 & 2 & NS \\
\hline Mammary gland & 0 & 1 & NS & 4 & 1 & NS \\
\hline Uterus & & & & 5 & 7 & NS \\
\hline Other & 14 & 4 & -- & 16 & 6 & -- \\
\hline
\end{tabular}

*The incidences shown are cumulative lifetime incidences; ${ }^{* *}$ Observation and dieting started when rats were aged 3 weeks; ${ }^{* * *}$ Includes rats killed on humane grounds; $†$ Based on age-standardized analysis; $--. P<0.001 ;--P<0.01 ;-$ $P<0.05$; (-) $P<0.1$. 
or subjected to dietary restriction $(80 \%$ of ad libitum) lived longer, suffered less from ageingrelated degenerative diseases, and developed highly significantly fewer benign and malignant neoplasms than groups fed ad libitum on high energy diets. Provisional data for 200 male and 200 female rats in this study are summarized in Table II. All the 400 rats in the study were 'unemployed' and so none of them were exposed occupationally to any toxic chemicals or dusts! Nevertheless just over $25 \%$ of them developed malignant cancers before the experiment was terminated.

\section{Conclusions}

Now it may be felt by those working the fields of occupational medicine and hygiene that the data shown in Table II hardly fit into a discussion of occupational cancer. In my view they do for it is far more likely that any cancer that a worker in any trade or profession develops will stem from his life-long smoking, eating, drinking and sexual activities than from his exposure to any particular chemical or dust at work. More importantly, if there are, as there may well be, weak occupational cancer hazards waiting to be discovered, epidemiological investigators who do not take into careful and full account life-style factors cannot hope to find them unless the type of cancer involved is normally quite rare.

\section{Acknowledgements}

The data shown in Table II are derived from the ' 1200 Rat Biosure Study', details of which are due to be presented at a conference on 'Biological Effects of Dietary Restriction' sponsored by the International Life Sciences Institute on March 5-7, 1990 in Washington DC. I am grateful to all those involved in generating these data, including $\mathrm{Mr}$ Geoffrey Conybeare, Dr Graham Tobin, Mr David Prentice, Dr Bernhard Matter, Dr Peter Donatsch, Dr David Kelly and Mr Peter Lee for permission to present, in preliminary form, the data in this Table.

\section{References}

1. Registrar General's Decennial Supplement for England and Wales 1970-72: Occupational Mortality, 1978.

2. MacMahon, B., Cole, P., Brown, J. Etiology of human breast cancer: a review. J Natl Cancer Inst 1973, 50: 21-42.

3. Haenszel, W. \& Hillhouse, M. Uterine-cancer morbidity in New York City and its relation to the pattern of regional variation within the United States. J Natl Cancer Inst 1959, 22: $1157-1168$

4. Doll, R. \& Peto, R. The causes of cancer: Quantitative estimates of avoidable risks of cancer in the United States today. J Natl Cancer Inst 1981, 66: 1191-1312.

5. Haenszel, W. Studies of migrant populations. J Chronic Dis 1970, 23: 289-291.

6. Butterworth, B.E. \& Slaga, T.J. (eds). Nongenotoxic Mechanisms in Carcinogenesis. Banbury Report 25: 1-397. Cold Spring Harbor Laboratory, New York, 1987.

7. Roe, F.J.C. How do hormones cause cancer? In Iverson, O.H. (ed). Theories of Carcinogenesis. Hemisphere Publishing Co, Washington, 1988, pp. 259-272.

8. Biskind, M.S. \& Biskind, G.R. Development of tumors in the rat ovary after transplantation into the spleen. Proc Soc Exp Biol Med 1944, 55: 176-179.

9. Gardner, W.U. Hormonal imbalances in tumorigenesis Cancer Res 1948, 8: 397-411.

10. Kirkman, H., Bacon, R.L. Estrogen-induced tumors of the Kidney - II. Effect of dose, administration, type of estrogen and age on the induction of renal tumors in intact male golden hamsters. J Natl Cancer Inst 1952, 13: 757-771.

11. Roe, F.J.C. \& Baer, A. Enzootic and epizootic adrenal medullary proliferative disease of rats: influence of dietary factors which affect calcium absorption. Hum Toxicol 1985, 4: $27-52$.

12. Roe, F.J.C. Non genotoxic carcinogenesis: implications for testing and extrapolation to man. Mutagenesis 1989, 4: 407-411.

13. Ames, B.N. Dietary carcinogens and anticarcinogens. Oxygen radicals and degenerative disease. Science 1983, 221: 1256-1264.

14. Ames, B.N. Mutagenesis and carcinogenesis: endogenous and exogenous factors. Environmental \& Molecular Mutagenesis 1989, 14 (Suppl. 16): 66-77.

15. Totter, J.R. Spontaneous cancer and its possible relationship to oxygen metabolism. Proc Natl Acad Sci 1980, 77: 1763-1767.

16. Roe, F.J.C. 1200 Rat Biosure Study. Design and overview results. Paper presented at Conference on Biological Effects of Dietary Restriction. Sponsored by International Life Sciences Institute in Washington D.C., U.S.A., March 5-7, 1990. 